\title{
Research Paper \\ Evaluating the Antimicrobial Properties of Glass Ionomer, Zinc Phosphate, and Polycarboxylate Cement
}

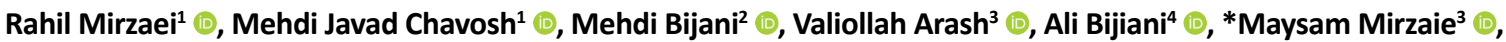 \\ Mohamad Mehdi Naghibi Sistani ${ }^{5}$ (c)
}

1 Department of Orthodontics, School of Dentistry, Babol University of Medical Sciences, Babol, Iran.

2. Department of Microbiology, Infectious Diseases and Tropical Medicine Research Center, Research Institute for Health, School of Medicine, Babol University of Medical Sciences, Babol, Iran.

3. Department of Orthodontics, Dental Materials Research Center, Research Institute for Health, School of Dentistry, Babol University of Medical Sciences, Babol, Iran.

4. Social Department of Health Research Center, Research Institute for Health, Babol University of Medical Sciences, Babol, Iran.

5. Oral Health Research Center, Health Research Institute, Babol University of Medical Sciences, Babol, Iran.

\begin{tabular}{|c|c|}
\hline $\begin{array}{l}\text { Use your device to scan } \\
\text { and read the article online }\end{array}$ & Citation: Mirzaei R, Chavosh MJ, Bijani M, Arash V, Bijani A, Mirzaie M, et al. [Evaluation of Antimicrobial Properties \\
\hline 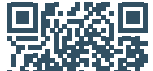 & $\begin{array}{l}\text { of Glass Ionomer, Zinc Phosphate and Polycarboxylate Cements (Persian)]. Journal of Arak University of Medical Sciences } \\
\text { (JAMS). 2021; 24(1):24-35. https://doi.org/10.32598/JAMS.24.1.6180.1 }\end{array}$ \\
\hline 回作政 & doi)'https://doi.org/10.32598/JAMS.24.1.6180.1 \\
\hline
\end{tabular}

\section{(1) (3)}

Article Info:

Received: 21 May 2020 Accepted: 29 Sep 2020 Available Online: 01 April 2021

Keywords:

Antibacterial effect adhesives, Orthodontics, Streptococcus mutans, Streptococcus sobrinus

\section{ABSTRACT}

Background and Aim There exists increased demineralization risk of enamel adjacent to fixed orthodontic attachments by cariogenic bacterias (e.g., Streptpcoccus mutans, Streptpcoccus sobrinus) and inadequate data about commonly used orthodontic cements. Thus, we evaluated the antibacterial effects of three common domestic and foreign orthodontic cements (Glass ionomer, Zinc phosphate, \& polycarboxylate) on two cariogenic pathogens (S. mutans \& S. sobrinus).

Methods \& Materials In this laboratory study, after culturing two standard strains of Streptococcus mutans and Subrinus bacteria and concentrating and diluting them, a direct contact test was used to evaluate the antibacterial properties of types of cement. The study groups $(n=5)$ included the following: three types of glass ionomer resilience cement, Hoffman's zinc phosphate and Hoffman's polycarboxylate, and three glass ionomer cement, zinc phosphate, and carboxylate from Aria Dent factory in Iran. The acquired data were analyzed using SPSS v. 17.

Ethical Considerations The present study was approved by Ethics Committee of Babol University of Medical Sciences (Code: MUBABOL.REC.1391.7).

Results In both types of culture media, containing Streptococcus mutans and Streptococcus subrinus bacteria, there was a significant difference between culture media containing 3 groups of cements respecting bacterial growth inhibition zone $(P<0.001)$. In general, The mean diameter of the inhibition zone was greater in Iranian polycarboxylate, compared to its foreign counterpart $(P<0.001)$.

Conclusion Glass ionomer cement demonstrated better antibacterial effect compared to zinc phosphate and polycarboxylate cements. There was also greater antibacterial effect of three tested cements on S.sobrinus than S.mutans. Iranian polycarboxylate showed stronger inhibition on both mentioned bacterias compared to the foreign one.

\section{* Corresponding Author:}

Maysam Mirzaie, PhD.

Address: Department of Orthodontics, Dental Materials Research Center, Research Institute for Health, School of Dentistry, Babol University of Medical Sciences, Babol, Iran.

Tel: +98 (11) 32291408

E-mail: maysam2352@gmail.com 


\section{Extended Abstract}

\section{Introduction}

I

n orthodontic treatment, fixed or movable devices are applied to correct the position of the teeth. For higher-quality treatment, most orthodontists prefer the use of fixed devices. Adhesives, including composites and cement, are applied to attach the bracket to the tooth. The success rate of orthodontic treatment with fixed devices depends on the quality and stability of the employed connecting materials [1]. The cause of rapid demineralization is the presence of large and persistent amounts of cariogenic microbes around the brackets and braces, i.e., improperly attached to the tooth [7]. The most important of which are Streptococcus mutans and Streptococcus subrinus [8]. To prevent caries and insufficient research concerning types of cement used in orthodontics, we aimed to apply the antibacterial properties of 3 common orthodontic types of cement (glass ionomer, zinc phosphate, \& polycarboxylate) on two common cariogenic bacteria (Streptococcus mutans \& Subrinus).

\section{Materials and Methods}

The present laboratory study used the standard strains of Streptococcus mutans (1601 PTCC) and Streptococcus sobrinus (1290 PTCC) to evaluate the relevant antimicrobial effects. The sample size was estimated to be 5 samples per cement. Despite 6 types of cement, a total of 60 samples were studied. The bacteria were cultured for 24 hours at $37^{\circ} \mathrm{C}$ in $2 \mathrm{~mL}$ of Brain Heart Infusion broth and reached the half McFarland standard. The direct Contact Test method was used to evaluate the antibacterial properties of cement [16]. The bacterial base suspension was placed in a container, containing agar; the test substance was added to the dish. The antibacterial effect prevents the growth of bacteria around the test substance and creates an aura of non-growth; the diameter of which indicates the intensity of this effect. With sterile punching, the wells of the same size were generated in Himedia environments, and the bacteria were cultured with a sterile swab in a grass culture medium. The wells were then covered with $50 \mu \mathrm{L}$ of the desired cement. The plates were incubated at $37^{\circ} \mathrm{C}$. On days 2 and 5 , the diameter of the no-growth halo around each well was measured with a digital caliper. Analysis of Variance (ANOVA) and t-test were used to analyze the obtained data.

\section{Results}

This study applied 60 media, including 30 Streptococcus mutans and 30 for Streptococcus subrinus. In each group, 10 media for zinc phosphate cement (5 media for Iranian zinc phosphate cement \& 5 media for Foreign zinc phosphate cement), 10 culture media for polycarboxylate cement ( 5 Iranian polycarboxylate cement media \& 5 media foreign polycarboxylate cement), and 10 culture media were used for glass ionomer cement ( 5 culture media for Iranian glass ionomer cement $\& 5$ culture media for foreign glass ionomer cement). In this study, the diameter of the growth inhibition zone around the types of cement in both culture media remained unchanged between days 2 and 5 (Tables $1 \& 2$; Figure 1).

In both culture media types, containing Streptococcus mutans and Subrinus bacteria, a significant difference was observed in the culture media between the 3 groups of cement concerning the diameter of the growth inhibition zone around them $(\mathrm{P}<0.000)$. The following results were obtained by paired-wise comparing the culture media of the two studied bacteria:

Table 1. The Mean \pm SD diameter of growth inhibition zone in two culture medium types

\begin{tabular}{llccc}
\hline Culture Medium & Type of Cement & No. & Mean \pm SD (in Millimeters) & P \\
\hline \multirow{2}{*}{ Streptococcus mutans } & Zinc phosphate & 10 & $23.80 \pm 0.78$ \\
& Polycarboxylate & 10 & $14.40 \pm 2.27$ \\
& Glass ionomer & 10 & $25.30 \pm 3.33$ & $35.40 \pm 1.34$ \\
Streptococcus subrinus & Zinc phosphate & 10 & $22.20 \pm 0.71$ \\
& Polycarboxylate & 10 & $40.20 \pm 0.87$
\end{tabular}


Table 2. The Mean \pm SD diameter of the growth inhibition of the inner and external production in two culture medium

\begin{tabular}{lcccc}
\hline Culture Medium & Type of Cement & No. & Mean \pm SD (in Millimeters) & P \\
\hline & Foreign zinc phosphate & 5 & $24.20 \pm 0.83$ & 0.586 \\
& Iranian zinc phosphate & 5 & $23.40 \pm 0.54$ & $12.40 \pm 0.54$ \\
Streptococcus mutans & Foreign polycarboxylate & 5 & $16.40 \pm 1.14$ & $<0.001$ \\
& Iranian polycarboxylate & 5 & $28.40 \pm 0.54$ & $<0.001$ \\
& Foreign glass ionomer & 5 & $22.20 \pm 0.83$ & 0.004 \\
& Iranian glass ionomer & 5 & $36.40 \pm 1.14$ & $34.40 \pm 0.54$ \\
Streptococcus subrinus & Foreign zinc phosphate & 5 & $20.20 \pm 0.83$ & $<0.001$ \\
& Iranian zinc phosphate & 5 & $24.20 \pm 0.83$ & $<0.001$ \\
\hline & Iranian polycarboxylate & 5 & $42.80 \pm 0.44$ & $37.60 \pm 0.54$ \\
\hline
\end{tabular}

There was a significant difference in culture media $(\mathrm{P}<0.000)$ containing mutants except for internal zinc phosphate and external zinc phosphate $(\mathrm{P}=0.586)$ as well as between Iranian zinc phosphate and Iranian glass ionomer $(\mathrm{P}=0.179)$. In culture media containing Sobrinus bacteria, there was no significant difference between foreign zinc phosphate and Iranian glass ionomer $(\mathrm{P}=0.168)$; however, in other cases, there was a significant difference $(\mathrm{P}<0.000)$.

\section{Discussion and Conclusion}

The present study findings indicated that the highest antibacterial effect was related to glass ionomer, zinc phosphate, and polycarboxylate, respectively.

The highest growth inhibition zone was observed around the cement of the culture media, containing mutans and sobrinus, respectively, related to glass ionomer cement, zinc phosphate, and polycarboxylate cement, in sequence. The mean general and discrete growth aura around the studied cement in culture media, containing sobrinus was larger than culture media containing mutans, i.e., significant. Consistent with the results of previous studies by Mota [10], Eick [21], and Slutsky [23], the antibacterial property of glass ionomer was higher than that in other types of cement and short-lived. Daugela [26] also stated that zinc phosphate suggested the strongest antibacterial activity, compared to other cement immediately after mixing. Their obtained data were inconsistent with those of our study; this discrepancy may be due to differences in the methods and materials used in the experiments. According to the current study results, the antibacterial effect of types of cement on the bacterium Subrinus is much greater than that of mutans. Compared with domestic and foreign production cement, in Mutans culture medium, foreign glass ionomer of Iranian type presented better results. Besides, in the culture medium of Subrinus, foreign glass ionomer and zinc phosphate were better. There was no difference between polycarboxylate in both culture media. As a result, these data can be generalized to specific brands in this study.

According to the achieved findings, the antibacterial effects of glass ionomer are more than those of the other two types of cement. Additionally, the antibacterial effects of the studied types of cement on Subrinus were stronger than those of Mutans.

\section{Ethical Considerations}

\section{Compliance with ethical guidelines}

The present study was approved by Babol University of Medical Sciences (Code: MUBABOL.REC.1391.7). 


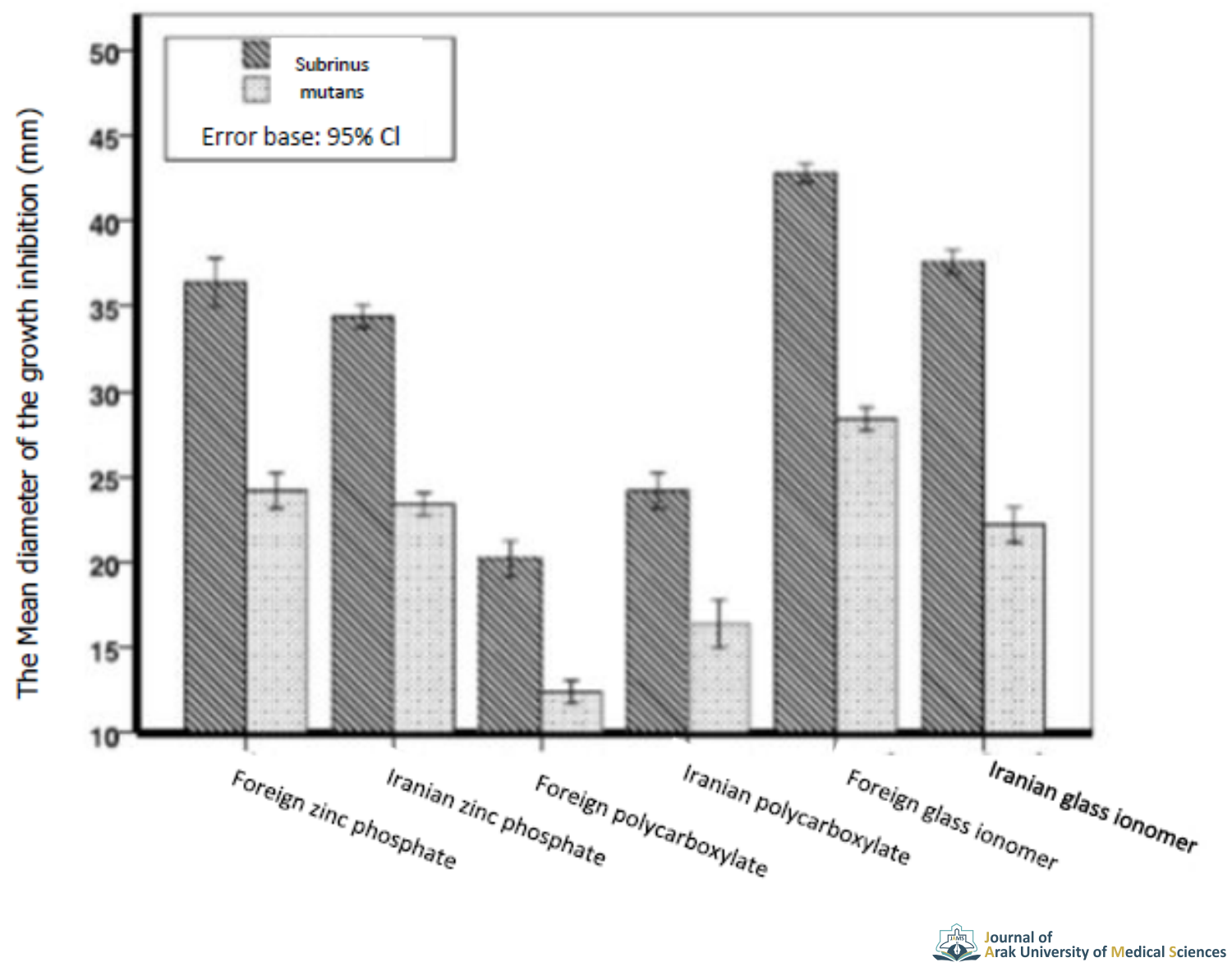

Figure 1. The average diameter of growth inhibition zone around the studied cement of domestic and foreign production in the studied culture media

Funding

This study was extracted from the $\mathrm{PhD}$. dissertation of the first author at the Department of Orthodontics, School of Dentistry, Babol University of Medical Sciences, Babol.

\section{Authors' contributions}

The authors met the standard criteria of the International Committee of Medical Journal Publishers (ICMJE) and contributed equally to the writing of the article.

\section{Conflicts of interest}

The authors declared no conflicts of interest.

\section{Acknowledgements}

The authors appreciate the contribution of the Dental Materials Research Center of Babol University of Medical Sciences to this study. 
This Page Intentionally Left Blank 


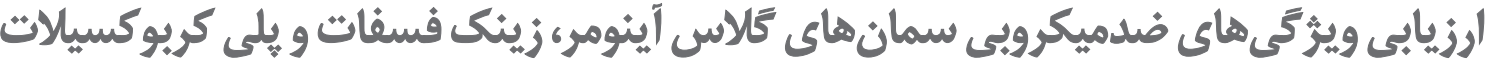

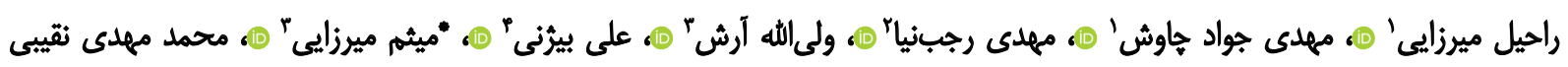
سيستانى" (1) ميرزئ

1. ا.تروه ارتوانتيكس، دانشكده دندانيزشكى، دانشكاه علوم يزشكى بابل، بابل، ايران.

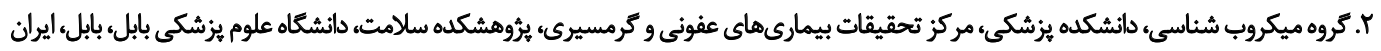

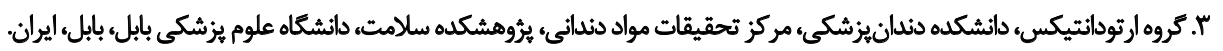

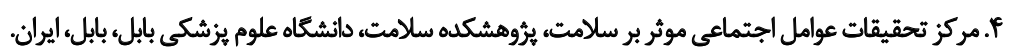

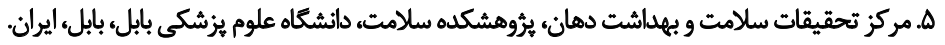

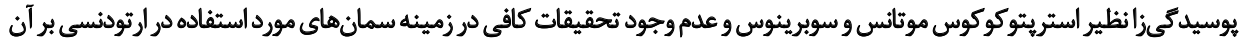

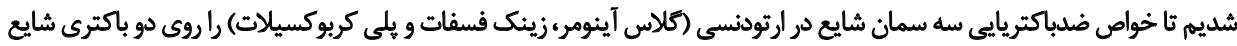

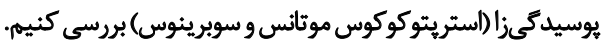

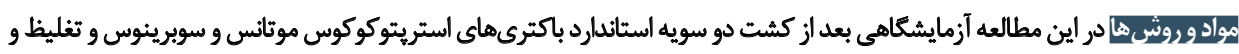

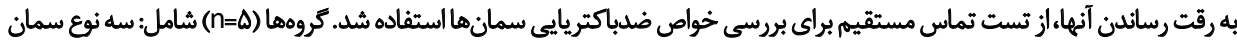

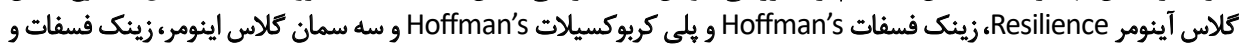

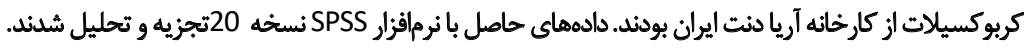

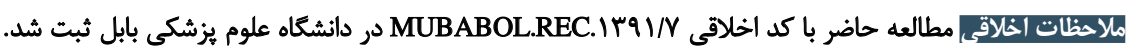

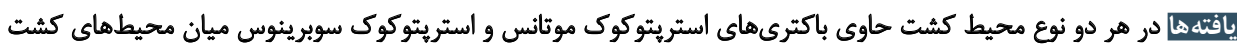

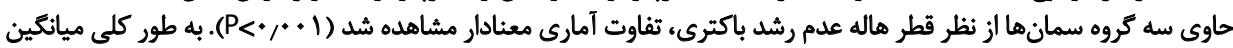

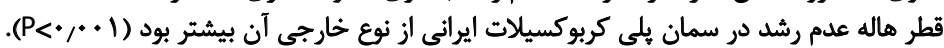

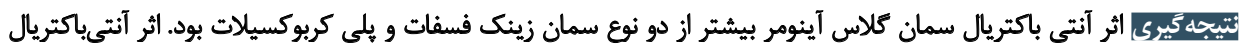

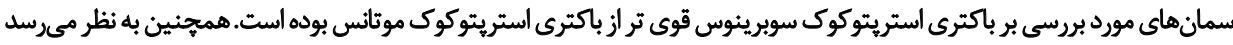

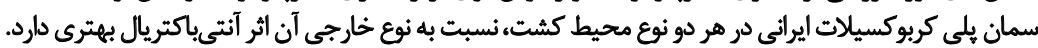

اطلاعات مقاله: تاريخ نريافت: ال•خرداد

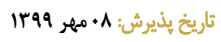

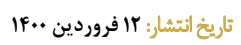

كليدواروها: آنتى باكتريال، سمان،

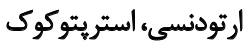
موتائس، استريتوكوك التريترك سوبرينوس

موفقيت درمان ارتودنسى با وسايل ثابت به كيفيت و ميزان ثبات

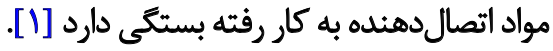

مقدمه

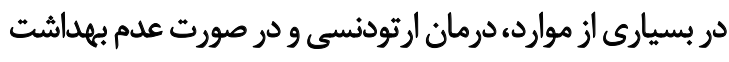

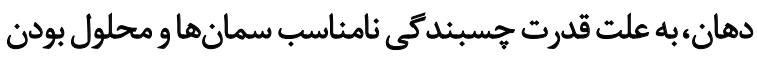

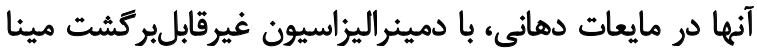

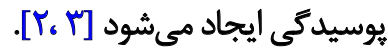

جهت تصحيح موقعيت دندانها، در درمان ارتودنسي، از وسايل

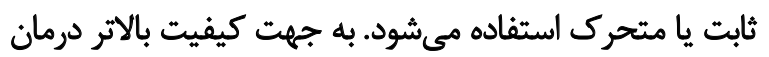

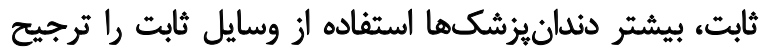

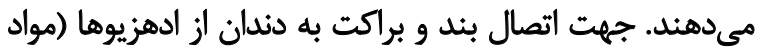

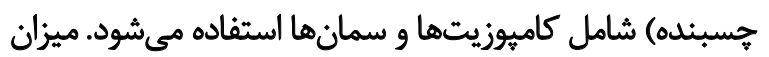


و در نتيجه مهار رشد آن مىشود [If].

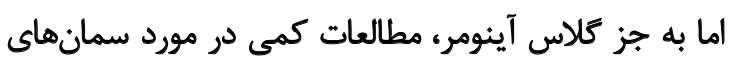

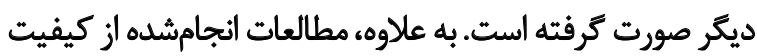

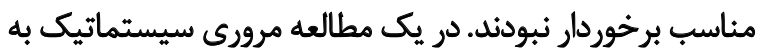

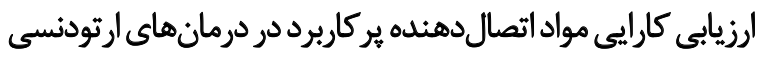

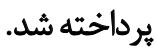

بدين منظور دو ييامد جهت ارزيابى اين مواد در نظر كرفته

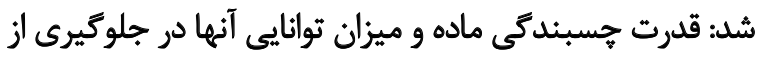

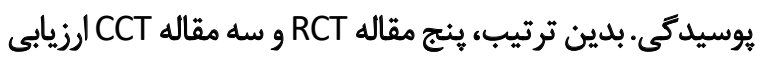

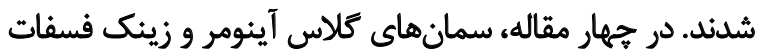

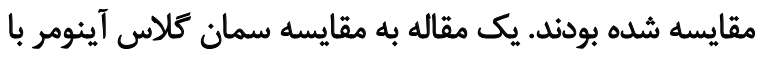

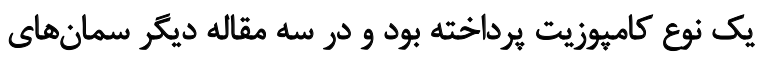

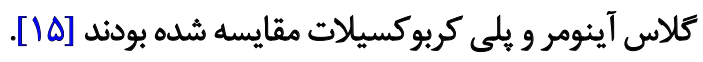

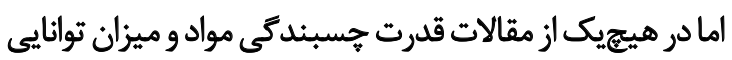

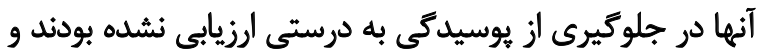

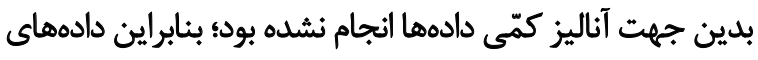

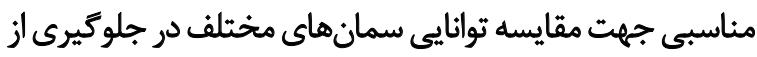
يوسيدكى وجود ندارد. لواف و همكاران [19] با ارزيابي مقايسهاي خاصيت

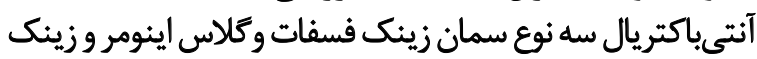

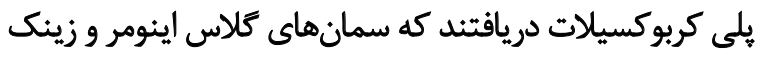
فسفات، فعاليت آنتى باكتريال دارند.

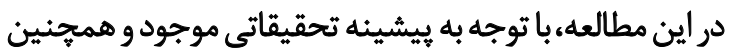

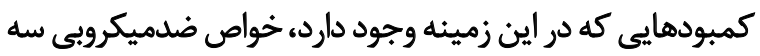

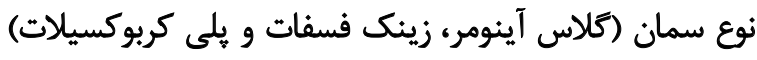

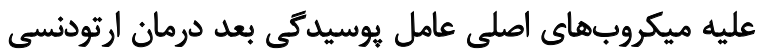

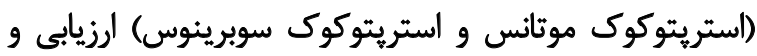

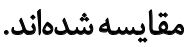

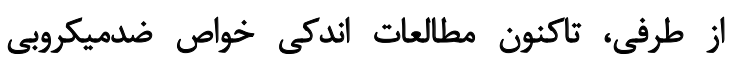

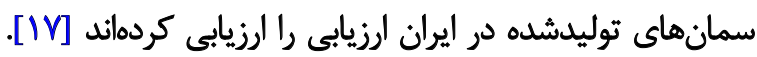

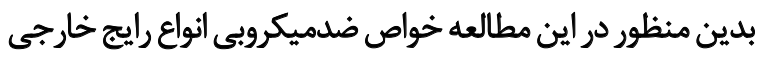
اين سمانها با يك نوع ايراني مقايسه شدرائ

\section{مواد ورش ماثها}

مطالعه حاضر، يك مطالعه آزمايشًاهى بود. در اين مطالعه

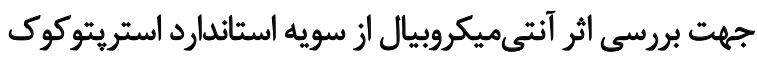

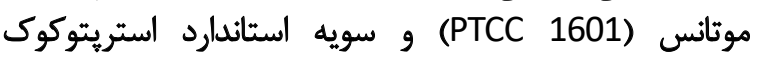
سوبرينوس (PTCC 1290) كه به طور شايع با يوسيدكى دندانى (PTCC مرتبط هستند، استفاده شد. بر اين اساس، حجم نمونه مورد نياز در اين مطالعه، معادل ينج

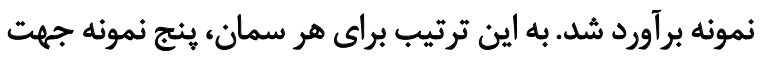

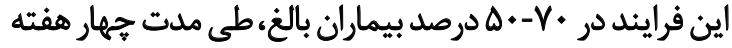

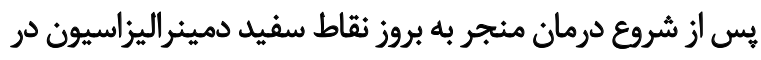

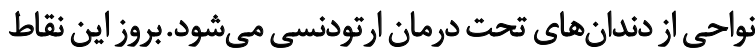

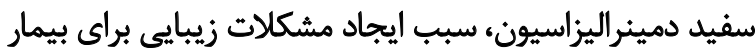

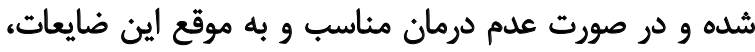

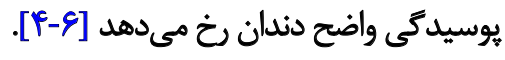

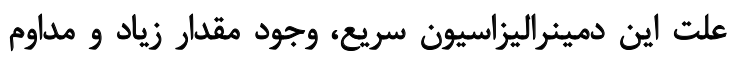

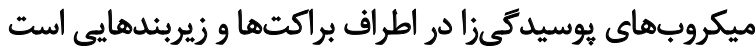

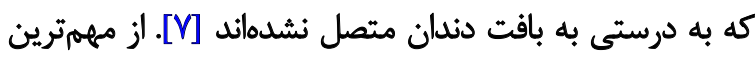

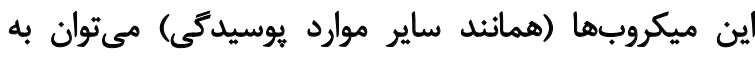
استريتوكوك موتانس و استريتوكوك سوبرينوس اشاره كرد [1/]. در واقع، محيط دهان تحت درمان ارتودنسى، دجار تغييراتى

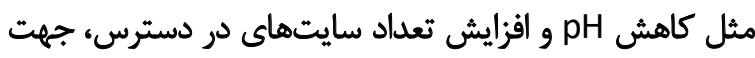

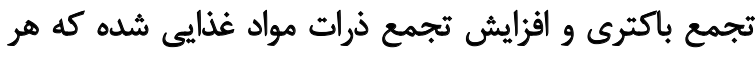

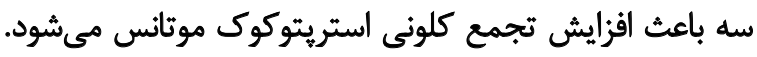

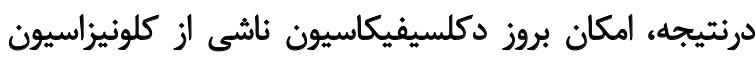

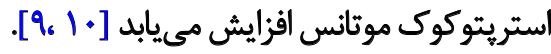

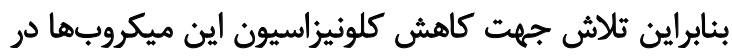

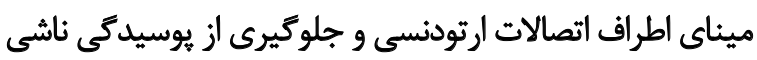
از آنها امرى لازم و ضرورى است.

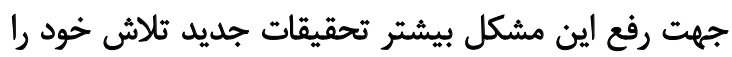

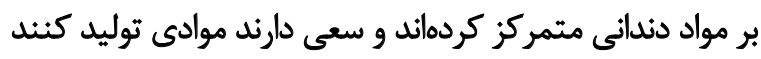

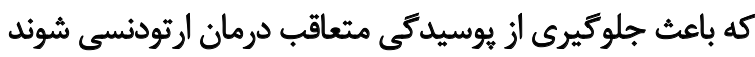

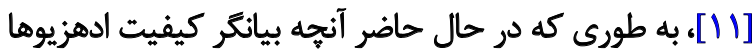

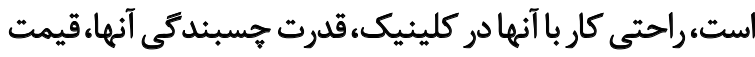

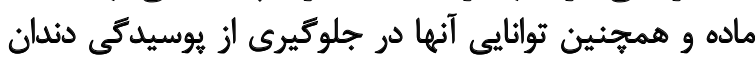

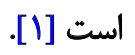

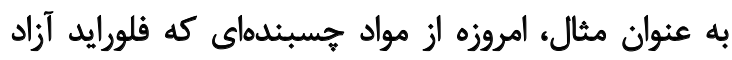

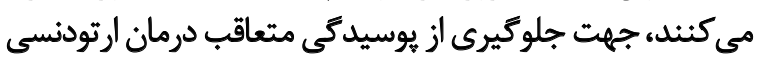

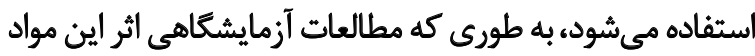

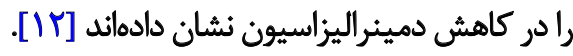
در اين ميان سمانها، كلاس آينومر بيشتر از ساير مواد

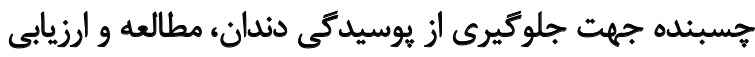

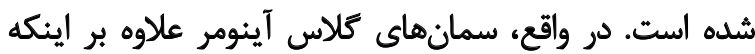

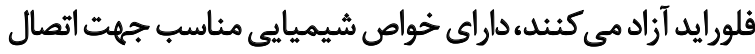

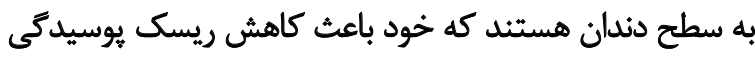

دندان مىشود [9].

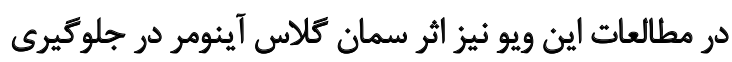

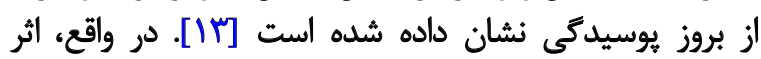

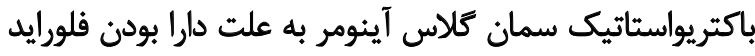

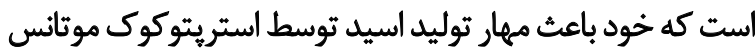




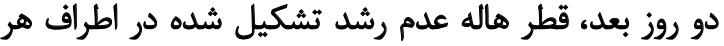

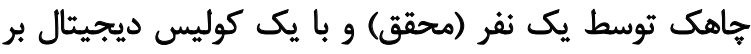

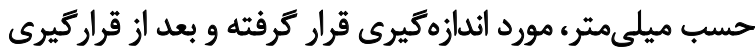

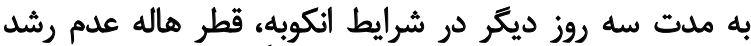

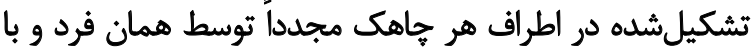

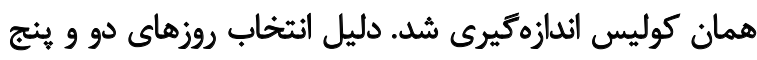

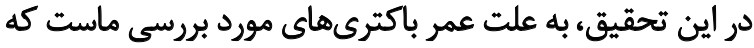

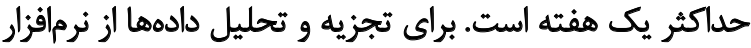

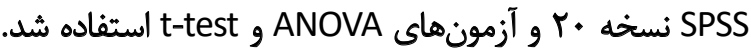

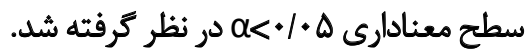

Latiol

نتايج نشان داد كه قطر هاله عدم رشد در اطراف سمانها در

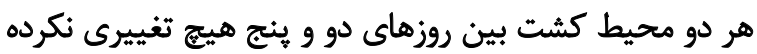

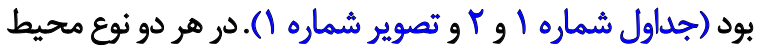

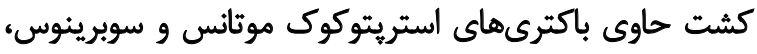

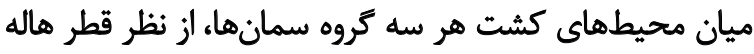

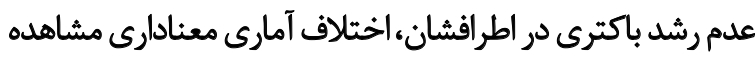

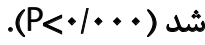

بيشترين قطر هاله عدم رشد به ترتيب مربوط به سمان كلاس

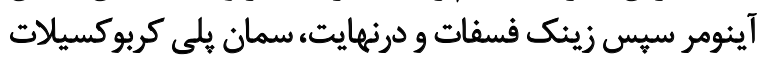

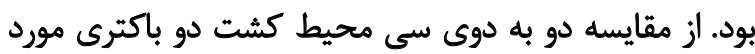
مطالعه نتايج زير حاصل شد:

در محيطهاى كشت حاوى باكترى استريتوكوكوس موتانس به به

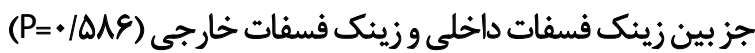

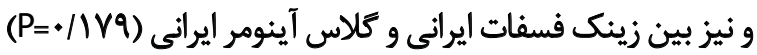

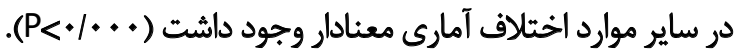

در محيطهاى كشت حاوى باكترى سوبرينوس فقط بين زينك

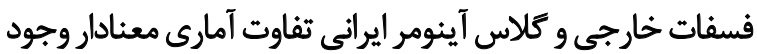

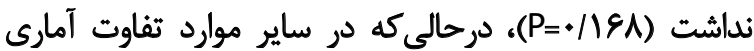

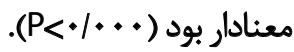

ث

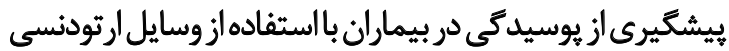

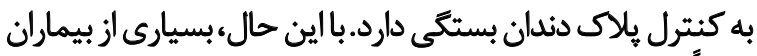

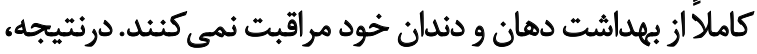

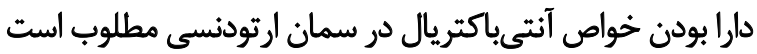

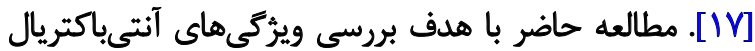

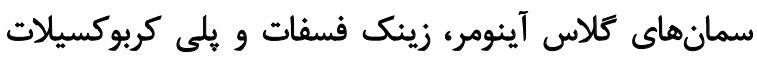
ايرانى و خارجى انجام كرفت.

يافتههاى مطالعه حاضر نشان مىدهد كه بيشترين اثر بئر

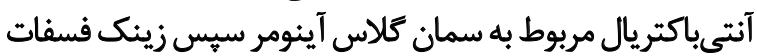

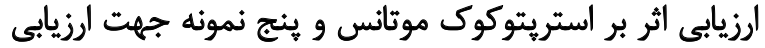

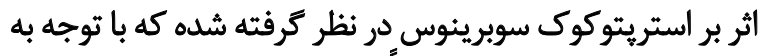

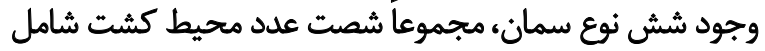

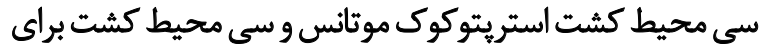
استريتوكوك سوبرينوس استفاده شد.

بدين ترتيب كه در هر كروه، ده محيط كشت براي سمانهاي

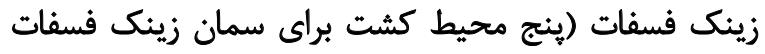

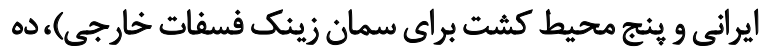

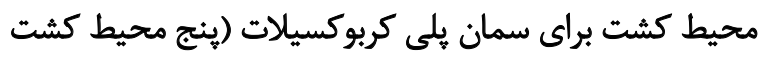

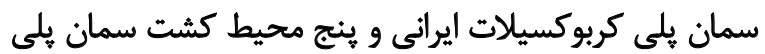

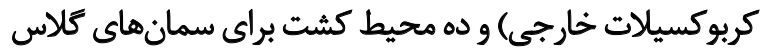

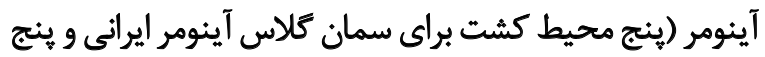

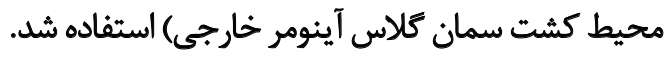

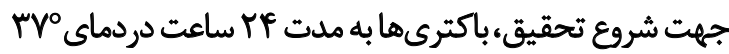

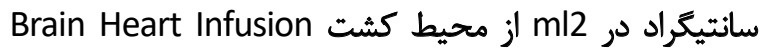

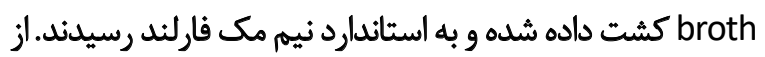

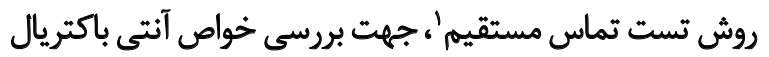

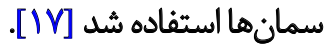
در اين تست سوسيانسيون بازيك باكترى، در ظرف إن حاوى آتار

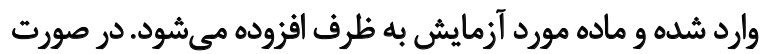

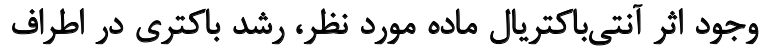

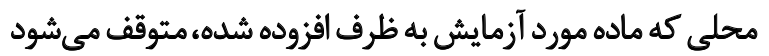
كه به ايجاد هالداى به نام هاله عدم رشد منجر مى شئود. وجود هاله عدم رشد به معناى بروز اثر آنتىباكتريال ماده مورد نظر و قطر آن بيانكر شدث اين اثر است. سه نوع سمان بان كلاس

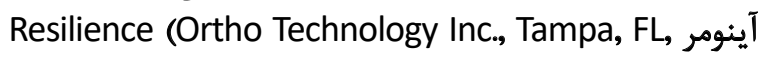
و Hoffman's (Hoffman, Germany) زينك فسفات, USA) يلى كربوكسيلات Hoffman's (Hoffman, Germany) طبق فيق

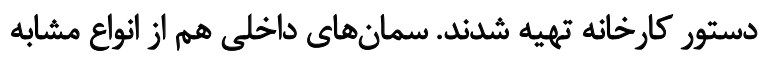
توليد شده از كارخانه آريادنت ايران (Apadana Tak, Iran)

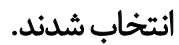

جهت تهيه نمونههاى سمان با قطر و ارتفاع يكسان، با پانج

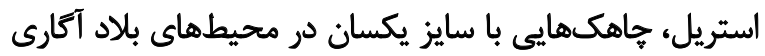

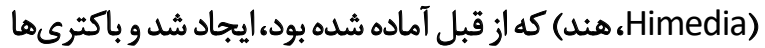

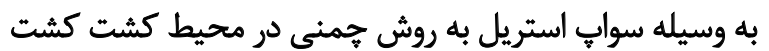

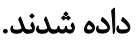

سيّ جاهك ها با سمانهاى مورد نظر، به ميزان يُنجاه

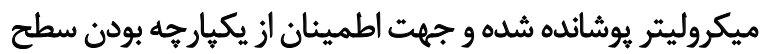

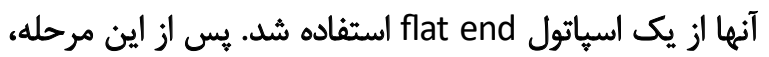

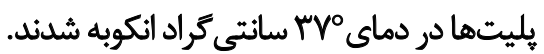

1. Direct Contact Test 
جدول ا. ميانكين قطر هاله عدم رشد در دو نوع محيط كشت مورد بررسى

\begin{tabular}{|c|c|c|c|c|}
\hline $\mathbf{P *}$ & انحرف معيار \$ميانكين (بر حسب ميلىمتر) & تعداد & نوع سمان & محيط كشت \\
\hline \multirow{6}{*}{$<+1++1$} & $r r / \Lambda \cdot \pm \cdot N \Lambda$ & 1. & زينك فسفات & \\
\hline & $\mid r / F+ \pm r / T Y$ & 1. & يلى كربوكسيلات & استريتوكوكوس موثانس \\
\hline & $r \Delta / T \cdot \pm T / N T$ & 1. & كاس آينومر & \\
\hline & $r \Delta / f \cdot \pm 1 / /{ }^{e}$ & 1. & زينك فسفات & \\
\hline & $M / r \cdot \underline{ \pm} \cdot M$ & 1. & يلي كربوكسيلات & استريتوكوكوس سوبرينوس \\
\hline & $r \cdot / r+ \pm \cdot / A V$ & 1. & كلاس آينومر & \\
\hline
\end{tabular}

*ANOVA

سمان كلاس آينومر داراى تأييد و ويرگكىهاى اساسى مانيند

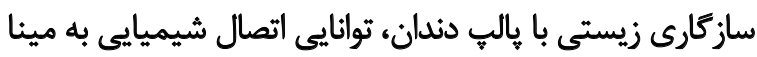

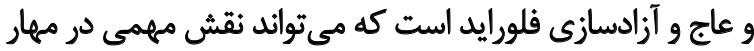

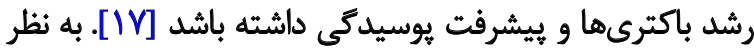

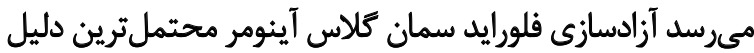

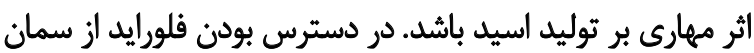

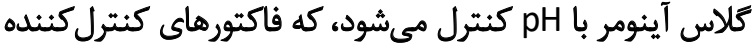

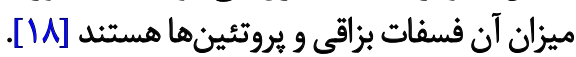

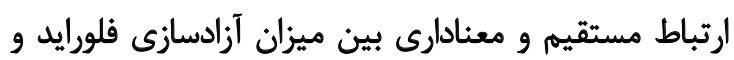

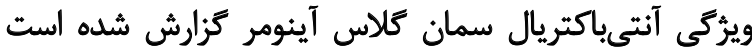

و درنهايت، سمان يلى كربوكسيلات بود. بيشترين هاله عدم رشد

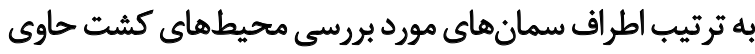

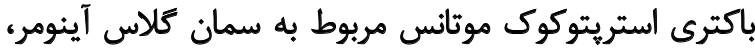

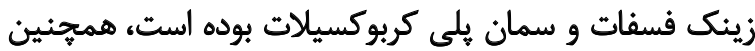

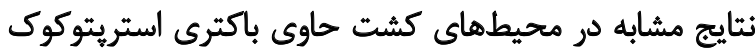

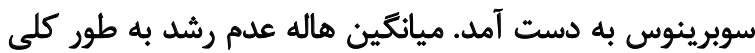

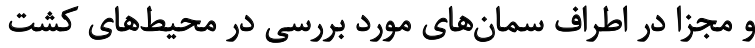

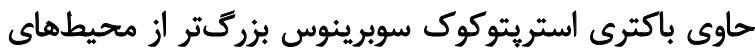

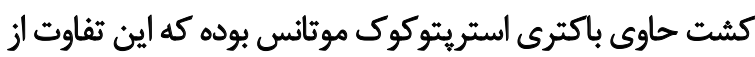

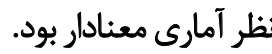

جدول r. ميانكين قطر هاله عدم رشد سمانهاي توليد داخلى و خارجى در دو نوع محيط كشت مورد بررسى

\begin{tabular}{|c|c|c|c|c|}
\hline P* & انحرف معيار_ميانكين (بر حسب ميلىمتر) & تعداد & نوع سمان & 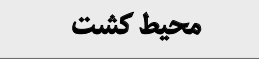 \\
\hline \multirow{2}{*}{.$/ \Delta N$} & $r \varphi / r+ \pm \cdot / A \mu$ & $ه$ & زينك فسفات خارجى Hoffman's & \multirow{6}{*}{ استريتوكوكوس موتانس } \\
\hline & $M / / F \cdot \pm \cdot / \Delta F$ & $\Delta$ & زيئك فسفات ايرانى (آريادنث) & \\
\hline \multirow{2}{*}{$<+1+\infty$} & $\left|T / f^{\circ} \cdot \pm \cdot / \Delta\right|^{f}$ & $\Delta$ & يلى كربوكسيلات خارجى Hoffman's & \\
\hline & $\mid \varepsilon / 4 \cdot \pm 1 / 16$ & $\Delta$ & يلى كربوكسيلات ايرائى (آريادنت) & \\
\hline \multirow{2}{*}{$<+1 .+1$} & $Y N P+ \pm \cdot / \Delta P$ & $\Delta$ & كاس آينومر خارجى Resilience & \\
\hline & $r / r \cdot \pm \cdot / A r$ & $ه$ & كلاس أينومر ايرائي (آريادنت) & \\
\hline \multirow{2}{*}{$.10 .+$} & $r e / \varphi+ \pm \backslash / / \varphi$ & $\Delta$ & زينك فسفات خارجى Hoffman's & \multirow{6}{*}{ استريتوكوكوس سوبرينوس } \\
\hline & $M T / F+ \pm+/ \Delta F$ & $\Delta$ & زينك فسفات ايراني (آريادنت) & \\
\hline \multirow{2}{*}{$<+1 .+1$} & $r+/ r+ \pm+/ A r$ & $\Delta$ & بلى كربوكسيلات خارجى Hoffman's & \\
\hline & $M \Psi / r \cdot \pm+/ \Lambda r^{2}$ & $\Delta$ & بلى كربوكسيلات ايرانى (آريادنت) & \\
\hline \multirow{2}{*}{$<+1++1$} & $F r / * \pm \cdot / F F$ & $\Delta$ & كلاس آينومر خارجى Resilience & \\
\hline & $r V / \varepsilon \cdot \pm \cdot \Delta / \Delta P$ & $\Delta$ & كلاس آينومر ايرائي (آريادنت) & \\
\hline
\end{tabular}




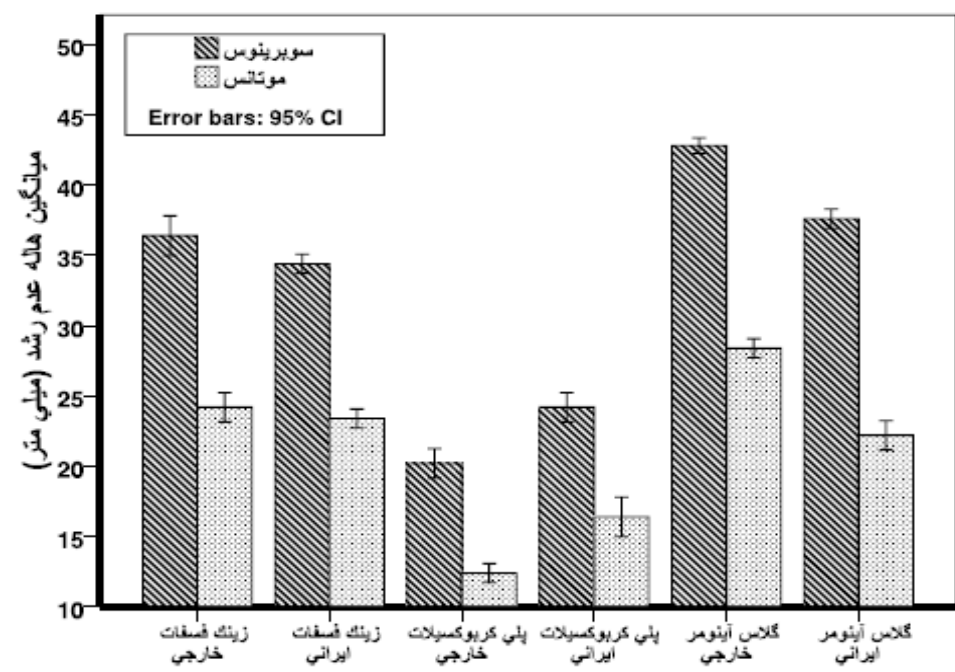

تصوير ا. ميانكين قطر هاله عدم رشد اطراف سمانهاى مورد بررسى توليد داخلى و خارجى در محيطهاي كشت مورد مطالعه

كلاس آينومر در مقايسه با سمانهاي ديكر. درنتيجه، كاربرد

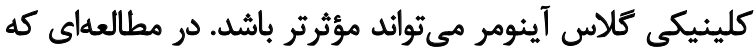

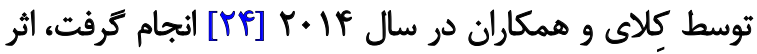

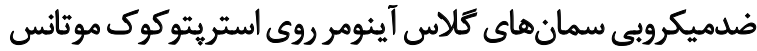

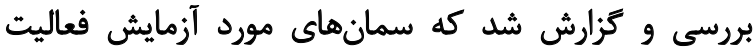

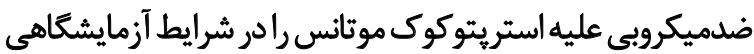

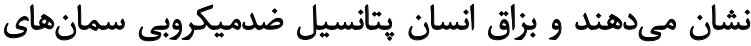

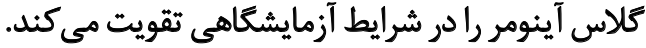

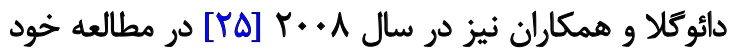

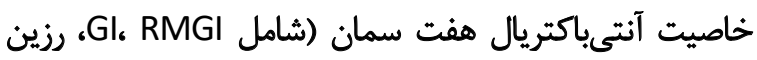
كاميوزيت، زينك فسفات، زينك يلي كريوكسيلات،

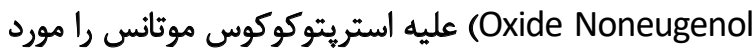
بررسى قرار داد و بيان كرد كه سمان زينك فسفات بلافاصله

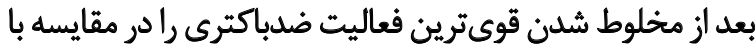

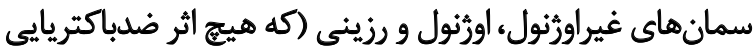

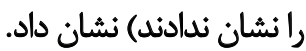

همجنين كلاس آينومرهاى غيرسخت، كريوكسيلات فعاليت ضدباكتريايى متوسط دارند. سمانهين انوماي

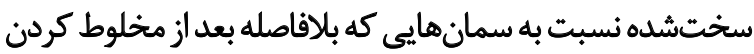

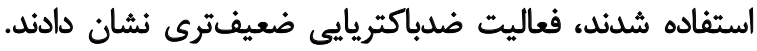

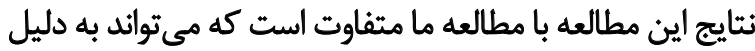

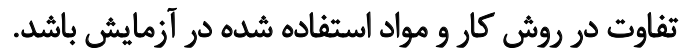

طبق نتايج حاصل از اين مطالعه، اثر آنتىباكتريال سمانها

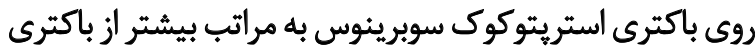

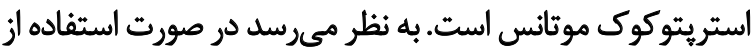

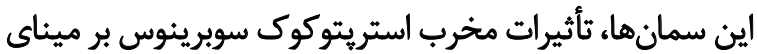

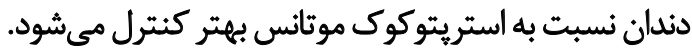

[19]. افزايش pH با كذشت زمان در سمان زينك فسفات و كاهش آزادسازي فلورايد در سمان كانلاس اينومر مي تونواند دانيل كاهش خاصيت آنتي باكتريال باشيد.

همجنين افزايش pH در سمان زينك فسفات نسبت به كاهش

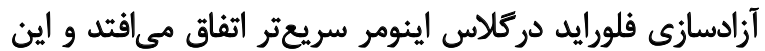

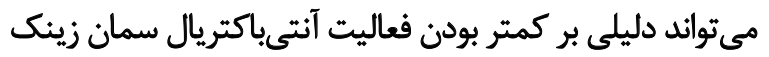

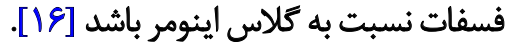
به طور مشابه از نتايج حاصل از مطالعات قبلى كه توسط لواف

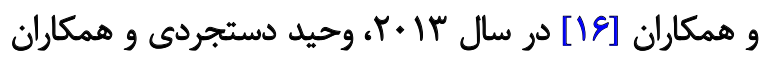

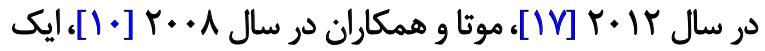

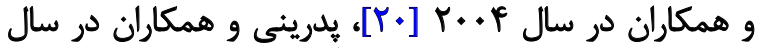

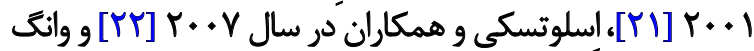

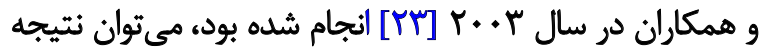

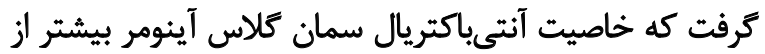

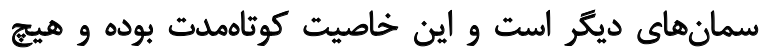

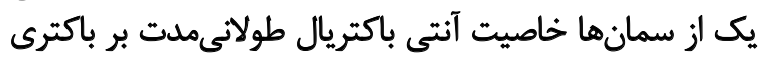

$$
\text { استريتوكوك موتانس نداشتند. }
$$

همجنين تغيير نكردن قطر هاله عدم رشد از روز دوم تا ينجمه،

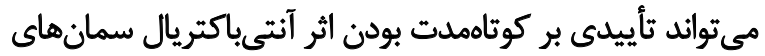

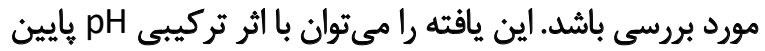

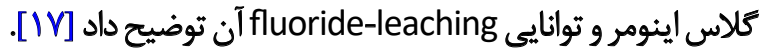

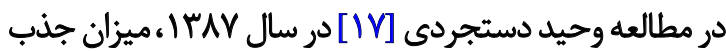

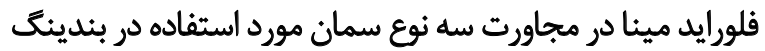

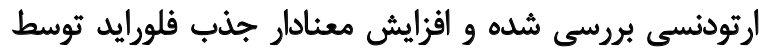

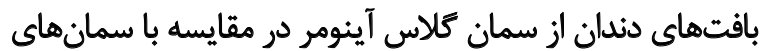

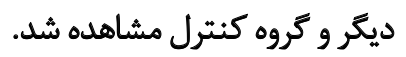
اين مطالعه نيز تأييدى است بر اثر آنتىباكتريال قوىثر سمان 


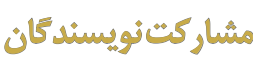

تمامى نويسندكان معيارهاى استاندارد نويسندكى بر اساس

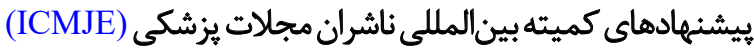

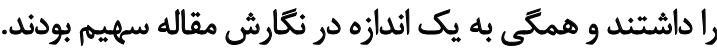

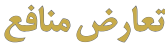

نويسندكان مقاله هيجّونه تعارضى در منافع اعلام نكردند.

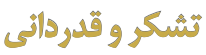

نويسندكان اين طرح تحقيقاتى بر خود لازم مئدانئد از

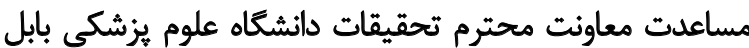

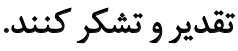

در مطالعه حاضر سمان يلى كربوكسيلات نيز داراى اثر

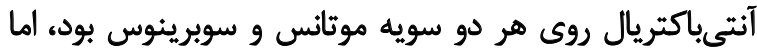

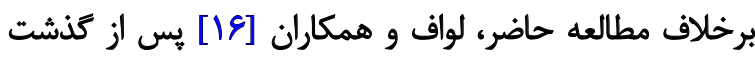

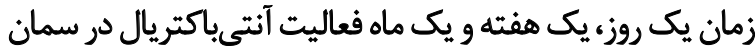

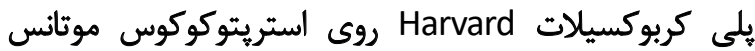

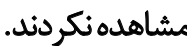

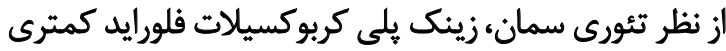

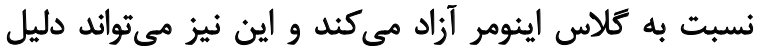

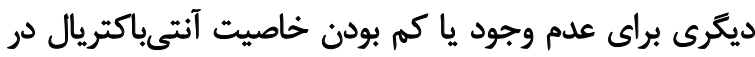

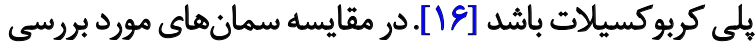

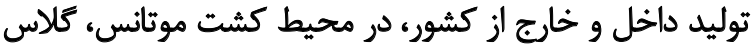

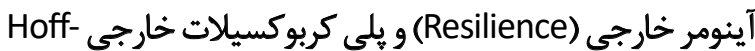

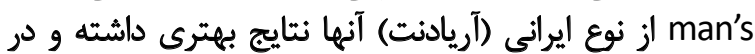

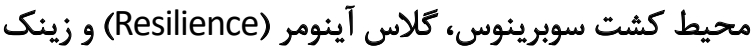
فسفات (Hoffman's) خارجى بهتر از نوع ايرانى آن بودهاند.

در محيط كشت استريتوكوكوس موتانس در نوع داخلى و

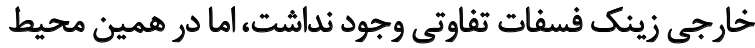
كشت يلى كربوكسيلات ايرانى (آريادنت) عملكرد آنتى باكتريال

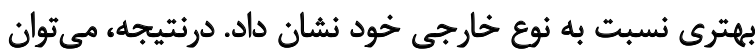

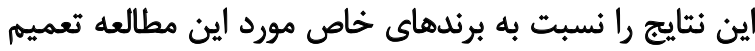

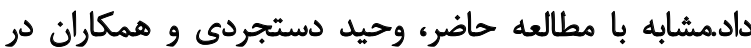

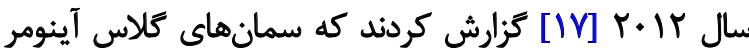

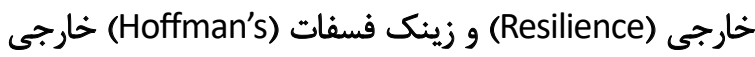

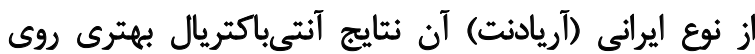

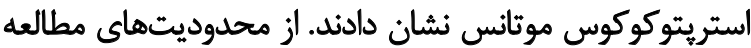

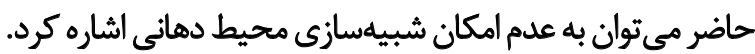

$$
\text { تثيجنميرى }
$$

با توجه به يافتههاى اين تحقيق، اثرات آنتىباكتريال سمان

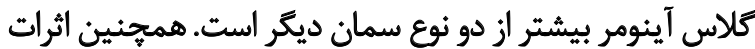

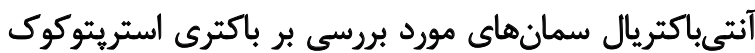
سوبرينوس قوىثر از باكترى استريتوكوك موتانس بودي.

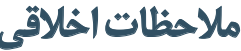

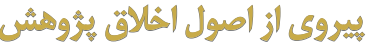

مطالعه حاضر مورد تاييد كميته اخلاق دانشكاه علوم يزشكى بابل قرار گرفته است (كد: MUBABOL.REC.13917).

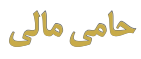

اين مقاله از باياننامه دكترى نويسندكان اول در كروهان

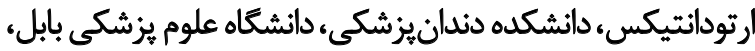

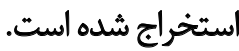




\section{Reference}

[1] Millett DT, Glenny AM, Mattick RC, Hickman J, Mandall NA. Adhesives for fixed orthodontic bands. Cochrane Database Syst Rev. 2016; 10(10):CD004485. [DOI:10.1002/14651858.CD004485.pub4] [PMID] [PMCID]

[2] Liebenberg WH. Extended fissure sealants: An adjunctive aid in the prevention of demineralization around orthodontic bands. Quintessence Int. 1994; 25(5):303-12. [PMID]

[3] van Beek H. [Risks of orthodontic treatment (Dutch)]. Ned Tijdschr Tandheelkd. 2009; 116(6):306-10. [PMID]

[4] Jordan CN. Prevention of white spot enamel formation during orthodontic treatment. Gen Dent. 1998; 46(5):498-502. [PMID]

[5] Matalon S, Slutzky H, Weiss El. Antibacterial properties of 4 orthodontic cements. Am J Orthod Dentofacial Orthop. 2005; 127(1):56 63. [DOI:10.1016/j.ajodo.2003.11.023] [PMID]

[6] Sudjalim TR, Woods MG, Manton DJ. Prevention of white spot lesions in orthodontic practice: A contemporary review. Aust Dent J. 2006; 51(4):284-9. [DOI:10.1111/j.1834-7819.2006.tb00445.x] [PMID]

[7] Ogaard B, Rolla G, Arends J. Orthodontic appliances and enamel demineralization. Part 1. Lesion development. Am J Orthod Dentofacial Orthop. 1988; 94(1):68-73. [DOI:10.1016/0889-5406(88)90453-2]

[8] Ogaard B, Rolla G. The in vivo orthodontic banding model for vital teeth and the in situ orthodontic banding model for hard-tissue slabs. J Dent Res. 1992; 71(3):832-5. [DOI:10.1177/0022034592071 00S08] [PMID]

[9] Cassanho ACA, Fernandes AM, Oliveira LD, Carvalho CAT, Jorge AOC, Koga-Ito CY. In vitro activity of zinc oxide-eugenol and glass ionomer cements on Candida albicans. Braz Oral Res. 2005; 19(2):134-8 [DOI:10.1590/S1806-83242005000200011] [PMID]

[10] Mota SM, Enoki C, Ito IY, Elias AM, Matsumoto MA. Streptococcus mutans counts in plaque adjacent to orthodontic brackets bonded with resin-modified glass ionomer cement or resin-based composite. Braz Oral Res. 2008; 22(1):55-60. [DOI:10.1590/S180683242008000100010] [PMID]

[11] Chadwick BL. Products for prevention during orthodontics. Br J Or thod. 1994; 21(4):395-8. [DOI:10.1179/bjo.21.4.395] [PMID]

[12] Erickson RL, Glasspoole EA. Model investigations of caries inhibition by fluoride-releasing dental materials. Adv Dent Res. 1995; 9(3):315-23. [DOI:10.1177/08959374950090031801] [PMID]

[13] Gorton J, Featherstone JDB. In vivo inhibition of demineralization around orthodontic brackets. Am J Orthod Dentofacial Orthop. 2003; 123(1):10-4. [DOI:10.1067/mod.2003.47] [PMID]

[14] Nakajo K, Imazato S, Takahashi Y, Kiba W, Ebisu S, Takahashi N. Fluoride released from glass-ionomer cement is responsible to inhibit the acid production of caries-related oral streptococci. Dent Mater. 2009; 25(6):703-8. [DOI:10.1016/j.dental.2008.10.014] [PMID]

[15] Chadwick BL, Roy J, Knox J, Treasure ET. The effect of topical fluorides on decalcification in patients with fixed orthodontic appliances: A systematic review. Am J Orthod Dentofacial Orthop. 2005; 128(5):601-6. [DOI:10.1016/j.ajodo.2004.07.049] [PMID]

[16] Lawaf S, Majd HE. [Comparison of antibacterial properties of three different dental cements by direct contact test (Persian)]. Jundishapur Sci Med J. 2013; 12(5):607-20. http://jsmj.ajums.ac.ir/article_49833.html?lang=en
[17] Dastjerdie EV, Oskoui M, Sayanjali E, Tabatabaei FS. In-vitro comparison of the antimicrobial properties of glass ionomer cements with zinc phosphate cements. Iran J Pharm Res. 2012; 11(1):77-82. [PMCID]

[18] Yadiki JV, Jampanapalli SR, Konda S, Inguva HC, Chimata VK. Com parative evaluation of the antimicrobial properties of glass ionomer cements with and without chlorhexidine gluconate. Int J Clin Pediatr Dent. 2016; 9(2):99-103. [DOI:10.5005/jp-journals-10005-1342] [PMID] [PMCID]

[19] Shashibhushan KK, Basappa N, Subba Reddy VV. Comparison of antibacterial activity of three fluorides- and zinc-releasing commercia glass ionomer cements on strains of mutans streptococci: An in vitro study. J Indian Soc Pedod Prev Dent. 2008; 26(S 2):S56-61. [PMID]

[20] Eick S, Glockmann E, Brandl B, Pfister W. Adherence of Streptococcus mutans to various restorative materials in a continuous flow system. J Oral Rehabil. 2004; 31(3):278-85. [DOI:10.1046/j.0305182X.2003.01233.x] [PMID]

[21] Pedrini D, Gaetti-Jardim Junior E, de Vasconcelos AC. Retention of oral microorganisms on conventional and resin-modified glassionomer cements. Pesqui Odontol Bras. 2001; 15(3):196-200. [DOI:10.1590/S1517-74912001000300004] [PMID]

[22] Slutsky H, Weiss El, Lewinstein I, Slutzky S, Matalon S. Surface antibacterial properties of resin and resin-modified dental cements. Quintessence Int. 2007; 38(1):55-61. [PMID]

[23] Wang SM, Hu W, Fu MK. [The inhibitory effect of glass ionomer cement for orthodontic bonding on bacteria (Chinese)]. Zhonghua Kou Qiang Yi Xue Za Zhi. 2003; 38(3):230-2. [PMID]

[24] Klai S, Altenburger M, Spitzmüller B, Anderson A, Hellwig E, AlAhmad A. Antimicrobial effects of dental luting glass ionomer cements on Streptococcus mutans. Sci World J. 2014; 2014:807086. [DOI:10.1155/2014/807086] [PMID] [PMCID]

[25] Daugela P, Oziunas R, Zekonis G. Antibacterial potential of contemporary dental luting cements. Stomatologija. 2008; 10(1):16-21 [PMID] 